\title{
Phonetic Categories of English and Korean Stops in 3-year-old Sequential Korean-English Bbilingual Children
}

Sue Ann Lee

Texas Tech University Health Sciences Center, TX, USA

Purpose: The purpose of the study was to examine phonetic categories of stop consonants produced by 3-year-old sequential Korean-English bilingual (KEB) children $(n=12)$.

Methods: Voice-Onset-Time (VOT) and vowel-onset fo (fo) of Korean and English stops were acoustically examined in each language separately. Then, their English and Korean stops were compared cross-linguistically.

Results: KEB children produced English voiced and voiceless stops as well as Korean fortis distinctively at all three places of articulation. However, they distinguished Korean lenis and aspirated stops with fo value, but not with VOT. In terms of English and Korean stops across languages, only English voiced and Korean fortis stops were distinctively produced whereas the other stops with long lag VOT were produced with similar VOT and fo values.

Conclusions: The findings of the current study suggest that sequential bilingual children possess two linguistic systems similar to simultaneous bilingual children.

Keywords: Stop, VOT, Sequential, Korean-English, Bilingual, Children

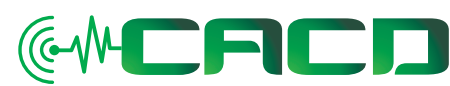

\section{INTRODUCTION}

The current study examined the acquisition of English and Korean stops produced by 3-year-old sequential Korean-English bilingual (KEB) children in order to investigate whether sequential KEB children make a phonetic distinction between first language (L1) and second language (L2).

How phonetic categories of bilingual children's respective languages are formed and interacted has been of interest because it provides an important insight to a longstanding theoretical question in bilingualism, that is, whether bilingual children develop one versus two linguistic system(s). The unitary system hypothesis $[1,2]$ argues that bilingual children employ linguistic rules common to both languages without differentiating the two systems. The dual system hypothesis, on the other hand, claims that bilingual children in fact differentiate both systems at an early age and these systems do not interact [3]. A third hypothesis is that bilingual children possess two systems at an early age, but these systems interact with each other $[4,5]$. Paradis and Genesee further hypothesized interaction between two languages results in three consequences in bilingual child's speech and language abilities. First, sounds that are specific

Received: September 20, 2016 Revision: November 28, 2016 Accepted: November 28, 2016

\section{Correspondence:}

Sue Ann S. Lee

Department of Speech-LanguageHearing Sciences, Texas Tech University Health Sciences Center, 3601 4th Street, Stop 6073, Lubbock, TX, 79430, USA Tel: +1-806-743-9051

Fax: +1-806-743-5670

E-mail: sueann.lee@ttuhsc.edu

(C) 2016 The Korean Association of SpeechLanguage Pathologists

This is an Open Access article distributed under the terms of the Creative Commons Attribution Non-Commercial license (http:// creativecommons.org/licenses/by-nc/4.0/) which permits unrestricted non-commercial use, distribution, and reproduction in any medium, provided the original work is properly cited. 
to one language will transfer to productions of the other language (i.e., transfer); second, speech and language development in bilingual children may emerge at a slower rate (i.e., deceleration); third, certain properties of speech and language abilities may emerge at a faster rate (i.e., acceleration).

Most research on these issues has been investigated in the lexical and syntactic domains. A limited number of studies have examined the phonetic domain. In particular, phonetic category development with "sequential" bilingual children is extremely rare since most studies focused on "simultaneous" bilingual children. Bilingual children are commonly categorized as either simultaneous or sequential [6]. Children who learn two languages from birth are designated as simultaneous bilinguals [7] whereas those who have acquired the L2 before the $\mathrm{Ll}$ is established are referred to as sequential bilinguals [8]. Based on these definitions, the participating children in this study were referred to as sequential bilingual children.

Further studies should be warranted with these sequential bilingual children because not every bilingual child simultaneously acquired two languages from birth. In particular, most Korean-English bilingual children from Korean families in the U.S. would be categorized as sequential bilingual children because these children start to be exposed consistently to English only when they are enrolled in English-speaking daycare centers, preschools or kindergartens, unless one of the parents is English-speaking [9]. Thus, the current study will provide important information regarding how Korean children learn English after they acquire a sound system of their Korean. Also the current study will provide insight on KEB children who are raised in Korea regarding how they acquire stop systems across two languages.

\section{BACKGROUND}

Deuchar and Quay [10] argued that the question regarding one system or two cannot be easily answered when segmental phonology is examined. Instead, acoustic investigation such as Voice-Onset-Time (VOT) or formant frequencies would provide a way to identify a child's underlying representation of a sound system. One of the earliest studies to examine phonetic category development of bilingual children was made by Deuchar and Clark [11]. English and Spanish stop consonants produced by a Spanish-English bilingual child were longitudinally examined at three ages $1 ; 7,1 ; 11$, and $2 ; 3$. At $1 ; 11$, voicing contrasts were found only for alveolar place of articulation in each language, but not for bilabial and velar places. Voicing contrast across English and Spanish languages
(English voiced vs. Spanish-voiced or English voiceless vs. Spanish voiceless) was not found either. At 2; 3, adult-like English stop distinctions was established; that is, voiceless stops were produced in the long-lag range while voiced stops were produced in the short lag range. However, both Spanish voiced and voiceless stops were produced within the short lag range, although they were significantly different from each other. In terms of across English and Spanish languages, voiceless stops were significantly different from each other whereas voiced stops were not until this age. The authors argued that there was not a single and unified English and Spanish system in the child and the greater differences of the lag between English stops pairs leads to the earlier acquisition of the pairs.

Another study was done by Johnson and Wilson [12] where they observed two Japanese-English bilingual children, one at 2; 10 and the other at 4; 8. Results showed that both children produced distinctive voiced and voiceless stops within each language. In terms of across languages, the older child differentiated English and Japanese in terms of the VOT of prevocalic bilabial and alveolar voiceless stops; however, the younger child was not able to differentiate them. Due to the limited number of participants, this study did not employ any statistical analysis. Thus, it was not certain whether such a difference was significant.

Kehoe, Lleo and Rakow [13] also examined three monolingual German children and four German-Spanish bilingual children who were raged from $1 ; 9$ to $3 ; 0$. They found that the monolingual children acquired the German voicing contrasts, whereas the four bilingual children showed a variety of patterns in each individual child. One child did not acquire voicing contrast in each language; one child produced voicing contrasts in each language but they were not realized phonetically; one child showed the presence of phonological and phonetic voicing contrast in German, but not in Spanish; one child demonstrated voicing contrast in both languages, but target-like voicing only appeared in German. These results suggested that the bilingual children showed either delay, transfer, or language independence in their acquisition of phonetic category development.

Recently, Fabiano-Smith and Bunta [14] examined VOT of voiceless bilabial and velar stops in 3-year-old Spanish-English bilingual children as compared to monolingual age equivalent peers. They found that bilingual children produced English stops differently from their monolingual peers, but Spanish stops were similar to Spanish-speaking children. In 
terms of cross-language contrasts, the bilingual children did not produce different VOT values for English and Spanish stops while VOT values of English and Spanish monolingual children were in fact different across languages. Unlike previous studies, a relatively larger number of bilingual children $(\mathrm{n}=8)$ participated in this study. However, the bilingual children in this study were either simultaneous bilinguals or child L2 learners. Thus, homogeneity of participants may affect the findings.

To our knowledge, there is only one study where phonetic category in a young sequential bilingual child was examined. Simon [15] reported a longitudinal case study examining the acquisition of English stops in a 3 year-old child who was a native speaker of Dutch. The child acquired Dutch from birth and was exposed to English at 3; 2. It should be noted that Dutch voiced and voiceless stops are produced with voicinglead and short-lag, respectively, that is similar to Spanish. The first recording was made 3 months after his exposure to English until 4; 0 in 11 sessions. She found significant differences in VOT distributions of voiceless stops across eleven sessions in both languages. At the 11th session, VOT of English stops was longer than Dutch stops. Regression analysis of voiced stops revealed a downward trend in percentage of Dutch prevoiced stops over the 11 sessions. The child produced $80 \%$ of voiced stops with voicing lead during initial sessions and the percentage went down to $30 \%$ at the last session whereas there was no trend in English voiced stops. The author claimed that the child differentiated between the two languages although they were not in a target-like manner.

In summary, only limited studies are available to examine phonetic category development in young bilingual children. Among the six studies, five studies employed only a small number of children ( 1 through 4 children), and only one study truly evaluated a sequential bilingual child. In addition, these previous studies studied English and another language contrasts whose voiced stops are often produced with voicing lead (e.g., Spanish, Dutch, and Japanese). Korean stops are of interest in that Korean stops are composed of three-way contrasts unlike other languages. Thus, examining how KEB children distinguish English and Korean stops will provide new information. A brief description of Korean stops as compared to English stops is provided as follows.

\section{English and Korean stops}

The English and Korean stop systems are compared in Table 1. English stops are commonly categorized as voiced and voice-
Table 1. Korean and English Stop Phonemes

\begin{tabular}{clccc}
\hline & & Labial & Alveolar & Velar \\
\hline \multirow{2}{*}{ Korean } & Fortis & $\mathrm{p}^{*}$ & $\mathrm{t}^{*}$ & $\mathrm{k}^{*}$ \\
& Lenis & $\mathrm{p}$ & $\mathrm{t}$ & $\mathrm{k}$ \\
& Aspirated & $\mathrm{p}^{\mathrm{h}}$ & $\mathrm{t}^{\mathrm{h}}$ & $\mathrm{k}^{\mathrm{h}}$ \\
\multirow{3}{*}{ English } & Voiced & $\mathrm{b}$ & $\mathrm{d}$ & $\mathrm{g}$ \\
& Voiceless & $\mathrm{p}$ & $\mathrm{t}$ & $\mathrm{k}$ \\
\hline
\end{tabular}

less based on VOT. VOT refers to the temporal interval between the release of stop closure and onset of voicing. Thus, English /b/ /d/ /g/ are categorized as voiced, /p//t/ /k/ as voiceless. Unlike English, Korean stops show a three-way laryngeal contrast and are distinguished by multiple cues. In particular, vowel-onset- $f_{0}$ (hereafter $f_{0}$ ) plays a role in addition to VOT. The three Korean stops are often called "lenis", "aspirated" and "fortis". The VOT values of Korean lenis and aspirated stops are longer than for fortis stops, while the $f_{0}$ values of Korean aspirated and fortis stops are higher than for lenis stops $[16,17,18]$. Among adult male speakers [18], Korean lenis stops are produced with long-lag VOT (44-66 ms) and low $f_{0}(120 \mathrm{~Hz})$, aspirated with long-lag VOT (74-97 ms) and high $f_{0}$ (147 Hz), fortis with short-lag VOT (10-24 ms) and high $f_{0}$ (139 $\mathrm{Hz}$ ). Recent research shows that the VOT values for phraseinitial lenis and aspirated stops are converging among contemporary, younger Seoul speakers, who distinguish these now only by $f_{0}$ [18]. In terms of place of articulation, the VOT values of alveolar and velar are longer than for bilabial place, but $f_{0}$ does not vary among the three places $[16,17]$.

\section{METHODS}

\section{Participants}

Twelve KEB children whose ages ranged from 3; 1 (year; month) to 3; 10 were recruited from Korean-speaking family in the United States. The bilingual children $(M=3 ; 4)$ acquired Korean first; then they were exposed to English when they attended English-speaking daycare centers. These children had been exposed to English for 6-8 months and attended Englishspeaking daycare centers at least 3 times per week if only Korean was spoken at home. None of the participating children had a history of speech or hearing impairment, based on reports from parents. In order to further establish normal development of communication skills, the children were examined using the Communication section of the Korean Age and Stage Questionnaire (K-ASQ) [19]. Test results confirmed that 
all children were within normal limits. When their English ability was tested using the Preschool Language Scale 4-Screening Test (PLS-4 Screening) [20], as expected, these sequential children were not able to follow directions or answer the questions. The children were only able to understand and answer basic questions such as "what is your name?" or "how old are you?" in English.

Based on the screening tests as well as interaction with the primary investigator, who is a certified Korean-English bilingual speech-language pathologist, each child's proficiency was rated for each language on a scale from 0 (child could not speak the indicated language at all) to 4 (child had native-like proficiency in the language), all of the bilingual children were rated as either 3 or 4 in Korean, but rated as 2 in English. These scales have been used in previous bilingual studies [21,22].

\section{Stimuli}

Table 2 shows the words containing target stops for English and Korean. These words were selected because of similar (if not always identical context), viz., non-high vowels following prevocalic stops, and because they are likely to be familiar to children as young as 3 years of age, with a few exceptions.

\section{Data collection procedure}

Picture naming tasks were used to elicit target stops. Since these children had limited knowledge of English vocabulary, they were asked to repeat all stimuli words that were pronounced by the primary investigator. When English words were being elicited, conversation was in English only, and when Korean words were elicited, all conversation was in Korean. Each word was elicited three times. A digital flash recorder (Marantz Model PMD670) and a wireless microphone (Sennheizer Model EW100) were used to record.

\section{Data analysis}

Multi Speech (Kay Elemetrics) was used to analyze the re-

Table 2. Target Words Used to Elicit English and Korean Stops

\begin{tabular}{|c|c|c|c|c|c|}
\hline & \multicolumn{2}{|c|}{ English } & \multicolumn{3}{|c|}{ Korean } \\
\hline & Voiced & Voiceless & Lenis & Aspirated & Fortis \\
\hline \multirow[t]{2}{*}{ Bilabial } & [bai] & [раг] & [pal] & [phal] & [p*ay] \\
\hline & bye & pie & foot & arm & bread \\
\hline \multirow[t]{2}{*}{ Alveolar } & [dat] & [tap] & [tal] & [thal] & {$\left[\mathrm{t}^{*} \Lambda \mathrm{k}\right]$} \\
\hline & dot & top & moon & mask & cake \\
\hline \multirow[t]{2}{*}{ Velar } & [gat] & [kap] & [kon] & {$\left[\mathrm{k}^{\mathrm{hal}}\right]$} & {$\left[k^{*} 0 t\right]$} \\
\hline & got & cop & ball & knife & flower \\
\hline
\end{tabular}

cordings. VOT and $f_{0}$ were obtained for each target word. VOT was measured from the beginning of stop release to the onset of voicing in the following vowel, using both waveforms and wide-band spectrograms. $f_{0}$ was measured at voicing onset with a $25 \mathrm{~ms}$ window from the first harmonic value in the Fast Fourier Transform (FFT) in the following vowel.

\section{Statistical analysis}

Statistical comparisons of VOT and $f_{0}$ values were completed using repeated measures ANOVA for each language and paired $t$-tests for within-subjects cross-linguistic comparisons. A significant level of $p<0.05$ was adopted. The Bonferroni correct was applied for multi comparisons.

\section{RESULTS}

The main goal of the current study was to examine phonetic category across English and Korean. Before we compared their English and Korean stops cross-linguistically, we compared stop production at each place of articulation within each language in order to understand their stop production in each language.

\section{VOT and fo comparisons of Korean stops}

Figure 1 shows means and standard deviations of VOT values of Korean stops produced by 3-year-old KEB bilingual children. A repeated measures ANOVA revealed a significant two way interaction between voicing type and place $(\mathrm{F}(4,44)=$ 2.95, $p=0.030)$. There were also significant main effects for voicing type $(\mathrm{F}(2,22)=27.37, p<0.001)$ and place $(\mathrm{F}(2,22)=$ 8.35, $p=0.002$ ). Pairwise comparisons (using $\alpha=0.05$ ) indicated that VOT values for Korean fortis stops were signifi-

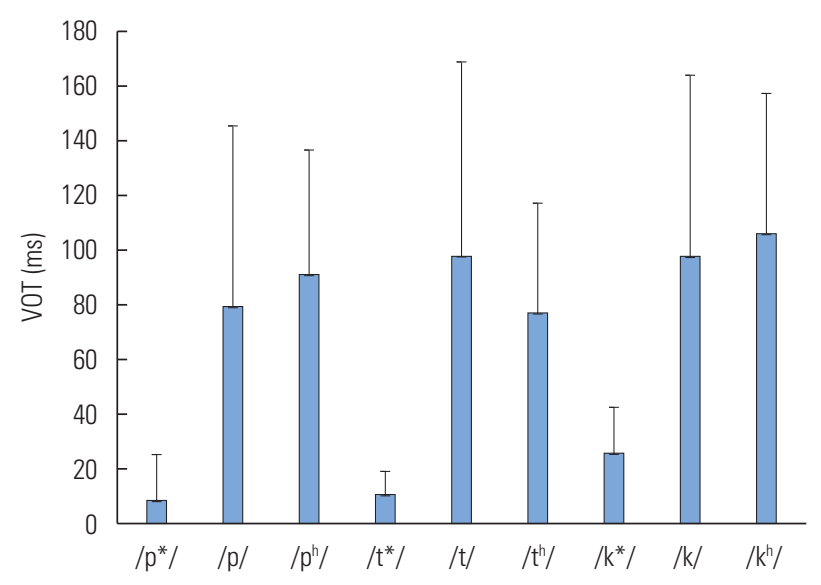

Figure 1. VOT values of Korean stops. 


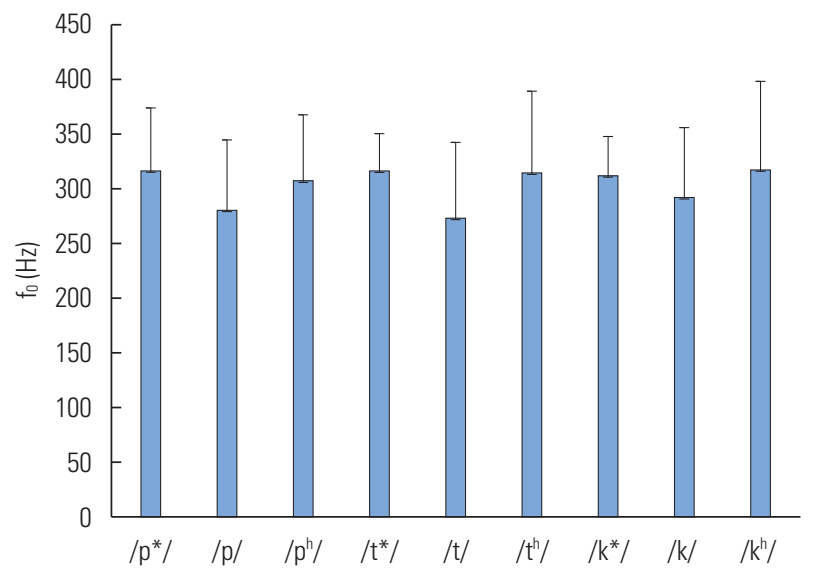

Figure 2. $f_{0}$ values of Korean stops.

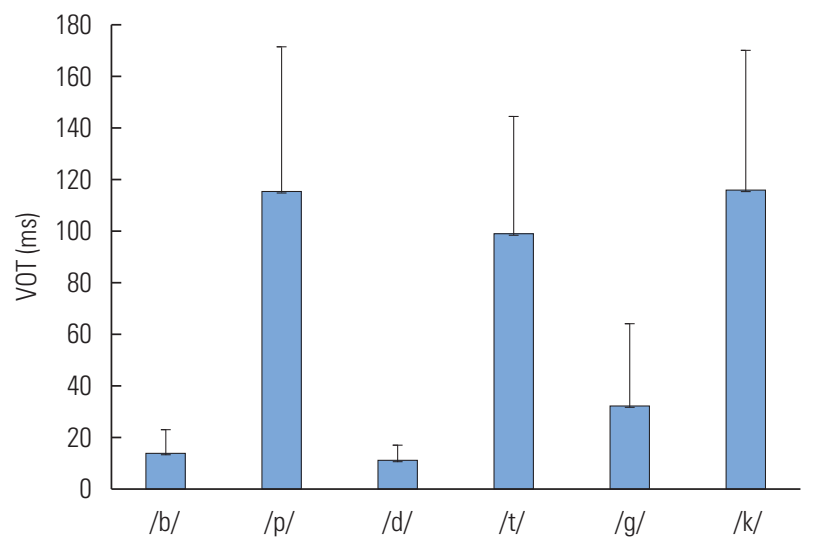

Figure 3. Shows means and standard deviations of VOT values of English stops.

cantly shorter than those of lenis and aspirated stops at three places of articulations; however, VOT values of Korean lenis and aspirated were not significantly different from each other at all three places.

Since the three-way contrast of Korean stops are distinctive based on $f_{0}, f_{0}$ values of the stops were also analyzed. Figure 2 shows means and standard deviations of $f_{0}$ values of Korean stops produced by 3-year-old KEB bilingual children. A repeated measures ANOVA revealed no significant two way interaction between voicing type and place $(\mathrm{F}(4,44)=.78, p=$ $0.50)$. The main effect for place $(\mathrm{F}(2,22)=0.21, p=0.80)$ was not significant, either. However, there were significant main effect for voicing type $(\mathrm{F}(2,22)=4.57, p=0.022)$. Post hoc comparisons (using $\alpha=0.05$ ) indicated that $f_{0}$ values of three Korean stops were significantly different from each other.

\section{VOT comparisons of English stops}

Figure 3 shows VOT values of voiced and voiceless English

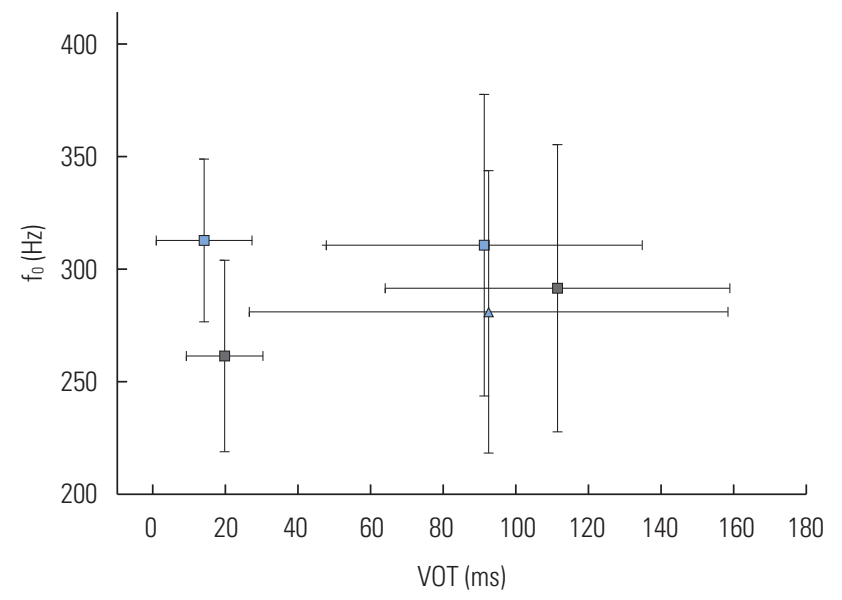

Figure 4. English and Korean stop categories in KEB children.

Table 3. VOT and fo comparisons across English and Korean Stop Pairs

\begin{tabular}{lcllcc}
\hline & VOT $(\mathrm{dF}=11)$ & & \multicolumn{3}{c}{$f_{0}(\mathrm{dF}=11)$} \\
\cline { 5 - 6 } \cline { 5 - 6 } & $t$ & & $p$ & $t$ & $p$ \\
\hline Voiced-lenis & -3.67 & & $0.004^{* * *}$ & -0.91 & 0.383 \\
Voiced-aspirated & -5.23 & & $0.000^{* * *}$ & -2.72 & $0.020^{*}$ \\
Voiced-fortis & 1.23 & & 0.242 & -3.67 & $0.004^{* * *}$ \\
Voiceless-lenis & 1.11 & & 0.29 & 0.58 & 0.572 \\
Voiceless-aspirated & 1.74 & & 0.110 & -1.22 & 0.246 \\
Voiceless-fortis & 7.25 & & $0.000^{* * *}$ & -1.21 & 0.252 \\
\hline${ }^{*} p<0.05 ;{ }^{* * *} p<0.01$. & & & & &
\end{tabular}

stops produced by KEB bilingual children. A repeated measures ANOVA revealed no significant two way interaction between voicing type and place $(\mathrm{F}(2,22)=.77, p=0.47)$. However, there were significant main effects for voicing type $(\mathrm{F}(1,11)=$ 45.13, $p<0.001)$ and place $(\mathrm{F}(2,22)=9.23, p=0.002)$. Post hoc comparison (using $\alpha=0.05$ ) indicated that VOT values for English velar stops were significantly longer than bilabial $(p=0.048)$ and alveolar $(p<0.001)$ stops.

\section{Comparisons across English and Korean stops}

Once we understood how KEB children produced Korean and English stop separately, we compared VOT and $f_{0}$ values across English and Korean languages in order to examine how KEB children make distinctive phonetic categories across the two languages. We examined each place of articulation separately and found the same patterns. Thus, we collapsed the data across the three places of articulation. Figure 4 shows VOT (x-axis) and $f_{0}$ (y-axis) of stops produced by KEB bilingual children for both English and Korean stops. The t-test results (Table 3) indicated that differences in VOT for English voiced- 
Korean lenis, English voiced-Korean aspirated, and English voiceless-Korean fortis were significant. However, only the English voiced-Korean aspirated and English voiced-Korean fortis pairs were significantly different with respect to $f_{0}$ values.

\section{DISCUSSION}

\section{English and Korean stops within each language}

Stop development in the English and Korean languages has been well established. Lowenstein and Nittrouer [23] reported that monolingual English-learning children stabilized voiced and voiceless stop phonemes at around 24 months. Bernthal, Bankson, and Flipsen [24] summarized that English voiced and voiceless phonological stop categories are fully developed by age 3. Kim and Stoel-Gammon [25] found that overall accuracy of stop consonants at 3 years of age was $71 \%$. When they become 3:6 years of age, overall stop accuracy increased to $82.3 \%$. In terms of acoustic parameters of stop consonants, 3; 6 year-old monolingual Korean children produced significantly different VOT for all three stops for bilabial, but not for alveolar and velar places. These children produced different VOT for fortis-lenis, and fortis-aspirated stops; but similar VOT for lenis-aspirated stops. In terms of $f_{0}$ values, the monolingual Korean children produced the highest $f_{0}$ for fortis followed by aspirated stops. $f_{0}$ values of these stops were significantly higher than lenis stops. These studies indicated that Korean stop contrasts appear to require a longer period of gestation than English stops, presumably because the stop system of Korean is more complex than that of English.

The current study examined stops produced by 3-year-old sequential KEB children. Based on previous studies [23,25], we found similar results with English-learning children; however, slightly different results from monolingual Korean children. While monolingual Korean children produced VOT for all three types of Korean stops for bilabial place at 3; 6 years of age, the age equivalent sequential KEB children produced similar VOT values for lenis and aspirated stops.

Paradis and Genesee [5] hypothesized three consequences resulting from interaction between two languages; transfer, acceleration, or deceleration. Kehoe et al. [13] found that a 3-year-old German-Spanish bilingual child did not acquire voicing contrast in each language and the other bilingual child at the same age produced voicing contrasts in each language but they were not realized phonetically. Deceleration was also found in previous studies of bilingual phonology studies $[26,27]$. However, based on the findings of the current study, it is difficult to argue that the sequential KEB children may show a delay in acquisition of distinctive Korean stop categories because the three way contrasts of Korean stops were still not distinctive at alveolar and velar places in monolingual Korean children [25].

\section{English and Korean stops across the two languages}

Among the five stop categories across English and Korean, only two stop categories were produced distinctively by 3-year-old sequential KEB children; that is, an English voiced stop and a Korean fortis stop. Although they were produced with similar VOT (i.e., short lag), $f_{0}$ values for these stops were significantly different from each other, establishing two separate categories. On the other hand, the three stop categories with long lag VOT (i.e., English voiceless, Korean lenis, and Korean aspirated) were not produced distinctively. They were produced with similar VOT and $f_{0}$ values. Thus, these finding indicated that the KEB children may have one phonetic representation for these three stops with long lag VOT.

The findings of the current study were, in part, consistent with Fabiano-Smith and Bunta [14] in that Spanish-English bilingual children did not produce English voiceless and Spanish voiceless stops with significantly different VOT values; VOT values of English voiceless stops were produced with much shorter VOT as compared to monolingual Englishspeaking children. However, this finding was different from Deuchar and Clark [12] that a Spanish-English bilingual child made a distinction between English and Spanish voiceless stops.

This finding is also different from Deuchar and Clark [11] in that KEB children in the current study did make a distinction between English voiced and Korean fortis stops whereas the English-Spanish bilingual child in their study did not make a distinction between English voiced and Spanish voiced stops. The different finding between the current study and Deuchar and Quay's [10] study may be attributed to the different characteristics of stops in Korean and Spanish. Spanish voiced stops develop later [28] as compared to English voiced stops [29]. Spanish voiced stops which are produced with a voicing lead was a challenge to young children. Korean fortis, on the other hand, is typically acquired the first among the three Korean stops [25]. Thus, making a phonetic distinction between English voiced and Korean fortis may be emergent earlier than the distinction between English voiced and Spanish voiced stops.

The three English and Korean stops with long lag VOT, on 
the other hand, seem to be difficult in making distinctive phonetic categories because KEB children cannot distinguish lenis from aspirated stop within the Korean language. Recall that KEB children produced Korean lenis and aspirated stops similarly with VOT values. Lenis stops are acquired latest among the three stops [25]. Distinguishing all three stops within long lag VOT categories may be too difficult for these children.

Based on our results, we concluded that bilingual children who were exposed to two languages at an earlier age may possess two separate phonetic systems; however, they need a longer exposure duration to produce these stops with full phonetic realization. The current study was, in part, consistent with Fabiano-Smith and Goldstein's [21] notion that "bilingual children perceive phonetically similar sounds as common between their two languages and categorize them into the same phonemic category (p. 193),"

\section{Limitations and future studies}

First, the current study examined only bilingual children without comparison of monolingual counterparts since monolingual children's stop development is fully established. However, future studies may need to make direct comparisons between bilingual and monolingual groups in order to examine whether sequential KEB children show a delay or transfer effect. Second, the current study examined KEB children who were raised in the U.S. It would be of interest if KEB children who are raised in Korea show similar or different VOT and $f_{0}$ characteristics from KEB children in the U.S. and if KEB children in Korea distinguish phonetic categories across English and Korean.

\section{CONFLICT OF INTEREST}

The author has no conflict of interests.

\section{ACKNOWLEDGMENTS}

This study was funded by NICHD (RHD061527A).

\section{REFERENCES}

1. Swain M. Bilingualism as a first language. Unpublished PhD dissertation. University of California, Irvine; 1972.

2. Volterra V, Taeschner T. The acquisition and development of language by bilingual children. J Child Lang. 1978;5(02):311-326.

3. Keshavarz M, Ingram $D$. The early phonological development of a Farsi-English bilingual child. Int J Bilingual. 2002;6(3):255-269.
4. Paradis J., Genesee, F. Syntactic acquisition in bilingual children: Autonomous or interdependent? Studies in Second Language Acquisition. 1996;18(01):1-25.

5. Paradis J. Do bilingual two-year-olds have separate phonological systems?. Int J Bilingual. 2001;5(1):19-38.

6. Goldstein B. Bilingual language development and disorders in Spanish-English speakers. Baltimore, Md.: P.H. Brookes Pub.; 2004.

7. Padilla A, Lindholm K. Child bilingualism: The same old issues revisited. In: Martinez I, Mendoza R, editors. Chicano Psychology. Academic Press, Orlando, FL; 1984.

8. Hamers J, Blanc M. Bilinguality and bilingualism. Cambridge: Cambridge University Press; 2000.

9. Shin S. Developing in two languages. Clevedon, England: Multilingual Matters; 2005.

10. Deuchar M, Quay S. Bilingual acquisition: Theoretical implications of a case study. New York: Oxford University Press; 2000

11. Deuchar M, Clark A. Early bilingual acquisition of the voicing contrast in English and Spanish. J Phonetics. 1996;24(3):351-365.

12. Johnson C, Wilson I. Phonetic evidence for early language differentiation: Research issues and some preliminary data. Int J Bilingual. 2002;6(3):271-289.

13. Kehoe M, Rakow M. Voice onset time in bilingual German-Spanish children. Bilingualism. 2004;7(1):71-88.

14. Fabiano-Smith L, Bunta F. Voice onset time of voiceless bilabial and velar stops in 3-year-old bilingual children and their agematched monolingual peers. Clin Linguist Phonet. 2011;26(2): 148-163.

15. Simon E. Child L2 development: A longitudinal case study on Voice Onset Times in word-initial stops. J Child Lang. 2009;37(01): 159-173.

16. Cho T, Jun S, Ladefoged P. Acoustic and aerodynamic correlates of Korean stops and fricatives. J Phonetics. 2002;30(2):193-228.

17. Oh E. Effects of speaker gender on voice onset time in Korean stops. J Phonetics. 2011;39(1):59-67.

18. Silva D. Acoustic evidence for the emergence of tonal contrast in contemporary Korean. Phonology. 2006;23(02):287-308.

19. Heo K, Squires J, Lee S, Lee J. Korean Age and Stage Questionnaire (K-ASQ). Seoul Community Rehabilitation Center: Seoul, Korea; 2006.

20. Zimmerman L, Steiner V.G, Pond RE. Preschool Language Scale-4 Screening Test. San Antonio, TX: PsychoCorp; 2005.

21. Fabiano-Smith L., Goldstein B. Phonological acquisition in bilingual spanish-English speaking children. J of Speech-Lang-Hearing Research. 2010;53:160-178.

22. Pena E, Bedore L, Rappazzo C. Comparison of spanish, English, and bilingual children's performance across semantic tasks. Lang Speech Hear Ser. 2003;34(1):5-16.

23. Lowenstein J, Nittrouer S. Patterns of acquisition of native voice onset time in English-learning children. J Acoust Soc Am. 2008; 124(2):1180-1191.

24. Bernthal J, Bankson N, Flipsen P. Articulation and phonological disorders. Boston: Pearson; 2013.

25. Kim M, Stoel-Gammon C. The acquisition of Korean word-initial stops. J Acoust Soc Am. 2009;125(6):3950-3961.

26. Gildersleeve-Neumann C, Kester E, Davis B, Pena E. English speech sound development in preschool-aged children from bi- 
lingual English-spanish environments. Lang Speech Hear Ser. 2008;39(3):314-318.

27. Goldstein B, Washington P. An initial investigation of phonological patterns in typically developing 4-year-old spanish-English bilingual children. Lang Speech Hear Ser. 2001;32(3):153-164.

28. Macken M, Barton D. The acquisition of the voicing contrast in
Spanish: a phonetic and phonological study of word-initial stop consonants. J Child Lang. 1980;7(03):42-66.

29. Macken M, Barton D. The acquisition of the voicing contrast in English: A study of voice onset time in word-initial stop consonants. J Child Lang. 1980;7(1):41-74. 